\title{
Bystander effects in bullfrog tadpoles
}

\author{
M. Audette-Stuart and T. Yankovich \\ Environmental Technologies Branch, Atomic Energy of Canada Limited (AECL), \\ Chalk River, Ontario, KOJ 1JO, Canada \\ e-mail: stuartm@aecl.ca
}

\begin{abstract}
Adaptive responses were observed using the micronucleus frequency in bullfrog tadpoles. In tanks in which control tadpoles were placed in contact with tadpoles that were previously housed in tritiated water $\left(3.0 \times 10^{4} \mathrm{~Bq} / \mathrm{L}\right)$, the cells from all animals responded as though they were "adapted". This suggests that direct exposure to $3.0 \times 10^{4} \mathrm{~Bq} / \mathrm{L}$ tritium contributes to an increased resistance to a high dose of radiation in liver cells. It also suggests that being in contact with tadpoles that were previously exposed to $3.0 \times 10^{4} \mathrm{~Bq} / \mathrm{L}$ tritium (bystander effect) contributes to an increased resistance to a high dose of radiation in liver cells.

In vitro exposures were also conducted using primary cultures of liver cells obtained from an unexposednon-bystander tadpole. In these control cells, it was observed that exposure to $100 \mathrm{mGy}$ of ${ }^{60} \mathrm{Co}$ gamma radiation (delivered at a dose rate of $5 \mathrm{mGy} / \mathrm{min}$ ) did not affect the micronucleus frequency whereas exposure to $4 \mathrm{~Gy}$ (delivered at a dose rate of about $10.2 \mathrm{~Gy} / \mathrm{min}$ ) increased the micronucleus frequency. Prior exposure to a low dose of ${ }^{60} \mathrm{Co}$ gamma radiation ( $100 \mathrm{mGy}$ delivered at a dose rate of $5 \mathrm{mGy} / \mathrm{min}$ ) induced an adaptive response, protecting the cells from harm caused by exposure to subsequent high doses of ${ }^{60} \mathrm{Co}$ gamma radiation (4 Gy delivered at a dose rate of about $10.2 \mathrm{~Gy} / \mathrm{min}$ ).

Using the adaptive response (determined using micronucleus assay) as a biomarker, the data obtained suggest that bystander effects do play a role in wild populations since bullfrog tadpoles that were not exposed to tritium responded like the tadpoles that were directly exposed to tritium after being placed in contact with them.
\end{abstract}

\section{INTRODUCTION}

Environmental radiation doses and dose rates (including the doses and dose rates expected in the vicinity of nuclear facilities) are generally well below those expected to produce mortality or significant measurable detrimental effects in resident biota. The doses can, however, be in the range where adaptive responses may be measurable. Using the micronucleus assay as a biomarker for radiation effects in liver cells obtained from bullfrog tadpoles, the effect of ${ }^{60} \mathrm{Co}$ gamma radiation exposure, effect of tritium exposure and the bystander effects (effects arising from the contact with bullfrog tadpoles that had previously been exposed to tritium) were evaluated.

The adaptive response is defined as the induction of resistance to a stressor, including high doses of ionizing radiation, by prior exposure to a small "adapting" stress. Chronic exposure to low doses (but above low background levels) can be considered an "adapting" stress. It should, however, be noted that such adaptation is not radiation-specific. It is an example of a more general stress response [1]. For example, cross-adaptation has been observed between exposure to radiation and metals [2], chemicals $[3,4]$ and hyperthermia $[5,6]$.

Experimentally, adaptive response experiments can be conducted in the laboratory by exposing cells to a low dose of ionizing radiation (delivered in a short time frame), allowing time for the cells to react (e.g. send some signals) and then exposing the cells to a high dose of ionizing radiation. If chronic exposure to slightly elevated levels of radiation affects the response to subsequent high radiation doses, bullfrog tadpole liver cell micronucleus frequency measurements could be used to measure such an adaptive response. For this reason, an adaptive response experiment was designed to investigate such 
effects of ${ }^{60} \mathrm{Co}$ gamma radiation exposure, effects of tritium exposure and bystander effects. Bystander effects can be defined as biological changes (such as micronucleus frequency) that occur following exposure to biota that were previously exposed to ionising radiation as opposed to biological changes that occur following direct exposure to ionising radiation (see for example [7]).

\section{MATERIALS AND METHODS}

\subsection{Tadpole capture, housing and tritium exposure}

Bullfrog tadpoles (Rana catesbeiana) were captured in Twin Lake, an area with relatively low (background) tritium levels (511 to $76 \mathrm{~Bq} / \mathrm{L}$, at the time of sampling). This area is located on the Atomic Energy of Canada Limited (AECL) Chalk River Laboratory (CRL) site, in Ontario, Canada. A great number of bullfrog tadpoles were present in Twin Lake. The number collected represented a very small fraction of the resident population. No detrimental environmental impact on the bullfrog populations was, therefore, expected as a result of sampling.

On 1 and 2 June 2005, tadpoles were collected using dip nets and placed into $20 \mathrm{~L}$ buckets containing Twin Lake water. In the Biological Research Facility (BRF), the tadpoles were placed in containers filled with $10 \mathrm{~L}$ of Twin Lake water. Five tadpoles were placed in each container. On 3 June 2005, a small quantity of tritium was added to each of the $3.0 \times 10^{4} \mathrm{~Bq} / \mathrm{L}$ containers. The tritium concentration represented about $10 \%$ of the target concentration. On 7 June 2005, the tritium concentration was increased to about $3.0 \times 10^{4} \mathrm{~Bq} / \mathrm{L}$. The tadpoles were kept in the $3.0 \times 10^{4} \mathrm{~Bq} / \mathrm{L}$ tritiated water for 57 days. A tritium concentration of $3.0 \times 10^{4} \mathrm{~Bq} / \mathrm{L}$ was chosen for this study it was possible to measure adaptive responses using the micronucleus assay following exposure to $3.0 \times 10^{4} \mathrm{~Bq} / \mathrm{L}$ in previous studies. During this study, the tritium concentrations fluctuated between 25,000 and $45,000 \mathrm{~Bq} / \mathrm{L}$. The room temperature was maintained at $20-21^{\circ} \mathrm{C}$ until 25 July 2005 . Afterwards the temperature was increased to $25^{\circ} \mathrm{C}$. As about $30 \%$ of the water was exchanged with pond water at least twice a week, the tadpoles were in an environment where small water temperature fluctuations were occurring on a regular basis. The water temperature was not monitored. During the water changes, the excrement, leftover food and debris were removed from the bottom of the containers. The tadpoles were kept in an environment with 12 hours of light and 12 hours of darkness each day. Tadpoles were fed a puree of boiled spinach kept frozen in ice cube trays and commercially available fish food. Quantities were adjusted so that very little food would be left at the time of the following feeding. Water changes and feedings were done during the day (light photoperiod) on an irregular schedule because it was reported to be better for the tadpoles and could help prevent them from accumulating excess fat (e.g. [8]).

The control tadpole was sacrificed on 8 August 2005. It was a female. Its liver micronucleus frequency following various ${ }^{60} \mathrm{Co}$ gamma radiation treatments ( $0 \mathrm{~Gy}, 100 \mathrm{mGy}, 4 \mathrm{~Gy}$ and $100 \mathrm{mGy}$ 3 hours prior to $4 \mathrm{~Gy}$ ) was determined. On 15 August 2005, tadpoles that were in tritiated water were transferred to a container filled with background water in preparation to conduct the bystander effect study (this served to clear the tritium and facilitate the handling of the animals). Physiological features were used to distinguish the tadpoles. The tadpoles were kept until 22 August 2005. Amongst the control tadpoles there were 3 males, one female and one for which the gender could not be determined. Amongst the tadpoles previously exposed to tritium, there were 4 males and one female. Prior to being euthanized, the tadpoles were transferred in background water. They were then placed in a container filled with icy water. The tadpoles were kept on ice for a few minutes, until cold torpor was reached. The tadpoles were then euthanized by percussion stunning followed by decapitation.

\subsection{Cell culturing, irradiation treatments and slide preparation}

The liver of each tadpole was aseptically removed and placed inside a sterile culture plate. The livers were covered with sterile phosphate-buffered saline solution (PBS) containing gentamycin. The PBS 
solution (5 L) was prepared using $40 \mathrm{~g} \mathrm{NaCl}, 1 \mathrm{~g} \mathrm{KCl}, 8.6 \mathrm{~g} \mathrm{Na}_{2} \mathrm{HPO}_{4} \cdot 7 \mathrm{H}_{2} \mathrm{O}$ and $1 \mathrm{~g} \mathrm{KH}_{2} \mathrm{PO}_{4}$ in deionized, distilled, filter-sterilized water. The $\mathrm{pH}$ was adjusted to 7.4 using dilute $\mathrm{HCl}$ and the volume was brought up to $5 \mathrm{~L}$. The PBS was filter-sterilized and was supplemented with a gentamycin solution: $5.5 \mathrm{~mL}$ of gentamycin (Invitrogen Canada Ltd., Burlington, ON) per $550 \mathrm{~mL}$ of PBS solution. The PBS solution was removed and replaced with $4 \mathrm{~mL}$ of culture medium, consisting of $50 \%$ Modified L-15 Leibovitz Culture Medium (Sigma-Aldrich Canada Ltd., Oakville, ON), 39\% deionized, distilled, filtersterilized water, $10 \%$ Fetal Calf Serum (Invitrogen Canada Ltd.) and 1\% gentamycin solution. Using sterile forceps, the extracted livers were rubbed against a sterile, small-meshed sieve. The process of physical separation released free cells from the liver, although a few tissue pieces were still visible. Eight milliliters of culture medium was added to the released cells and about $2 \mathrm{~mL}$ of the resulting cell suspension (expected to yield about $1 \times 10^{7}$ cells $/ \mathrm{mL}$ ) was transferred to four T-25 culture flasks. The cultures were then placed at an angle and incubated at room temperature (about $21^{\circ} \mathrm{C}$ ). A few hours later, the cells were exposed to a series of ${ }^{60} \mathrm{Co}$ gamma irradiation treatments: $0 \mathrm{mGy}+0 \mathrm{~Gy}$, $100 \mathrm{mGy}+0 \mathrm{~Gy}, 0 \mathrm{mGy}+4 \mathrm{~Gy}$ and $100 \mathrm{mGy}+4 \mathrm{~Gy}$. The low dose (100 mGy) was delivered at a dose rate of $5 \mathrm{mGy} / \mathrm{min}$ using a Gamma Beam located in the BRF and the high dose (4 Gy) was delivered 3 hours later at a dose rate of about $10.2 \mathrm{~Gy} / \mathrm{min}$ using a GammaCell 220 located in building 513. During the 3 hours waiting period, the cultures were kept at $21^{\circ} \mathrm{C}$ (without $\mathrm{CO}_{2}$ ) in the T-25 flask with the cap loosened to allow air exchange. With the exception of radiation exposure, all test flasks were treated the same way. The flasks were incubated for 48 hours prior to conducting the micronucleus assay. In preparation for the micronucleus assay, a cytochalasin B solution $(15 \mu \mathrm{L} / \mathrm{mL}$ of test culture $)$ was added to the cell cultures, 30 minutes after the high dose was delivered.

The cultures were gently aspirated to dislodge the cells from the culture flask walls. The suspension was then transferred to a $15 \mathrm{~mL}$ polypropylene centrifuge tube and the cultures were centrifuged at $150 \times g$ for $8 \mathrm{~min}$ at $7^{\circ} \mathrm{C}$. Most of the supernatant was removed and the pellet was gently resuspended in the remaining supernatant. Soft fixative solution $(0.75 \mathrm{~mL}$ of $10 \%$ acetic acid) was added to the cells. After $5 \mathrm{~min}, 0.75 \mathrm{~mL}$ of fixative solution (3:1 methanol/acetic acid containing $10 \%$ formaldehyde) was also added. Five minutes later, the cells were centrifuged. Most of the supernatant was removed and the pellet was resuspended in $1.5 \mathrm{~mL}$ of fixative solution (3:1 methanol/acetic acid). Following a standing time of $5 \mathrm{~min}$, the cells were centrifuged again and the supernatant was replaced with some fresh fixative. The slides were immediately prepared by dropping $12 \mu \mathrm{L}$ of the cell suspension onto each slide. The slides were flushed three times with fixative (3:1 methanol/acetic acid) and then dried over a hot water bath $\left(80^{\circ} \mathrm{C}\right)$. Slides were stained for 60 to $120 \mathrm{~s}$ in acridine orange dye $(50 \mu \mathrm{g} / \mathrm{mL}$; BDH Inc., Toronto $\mathrm{ON}$ ) and then rinsed twice with deionized, distilled water. A cover slip was placed over the cells. The slides were stored in the dark at room temperature until evaluation.

\subsection{Determination of the micronucleus frequency}

Coded liver cell slides were scored under a fluorescence microscope (fitted with a FITC filter cube) at $400 \times$ magnification, according to the criteria described in [9]. One thousand binucleate cells (BNC) were scored per treatment for the presence of micronuclei $(\mathrm{MN})$.

The data were reported as the MN frequency (number of MN per $100 \mathrm{BNC}$ ) as calculated using the following equation:

$$
\begin{aligned}
& M N \text { frequency }(M N / 100 B N C)= \\
& \frac{((\# B N C \text { with } 1 M N)+2(\# B N C \text { with } 2 M N)+3(\# B N C \text { with } 3 M N))}{\# B N C}
\end{aligned}
$$

The standard deviation of the MN frequency was calculated using the following equation:

$$
S T D=\sqrt{\frac{(\# B N C+\# M N)}{(\# B N C \bullet \# M N)}} \bullet \frac{\# M N}{\# B N C}
$$




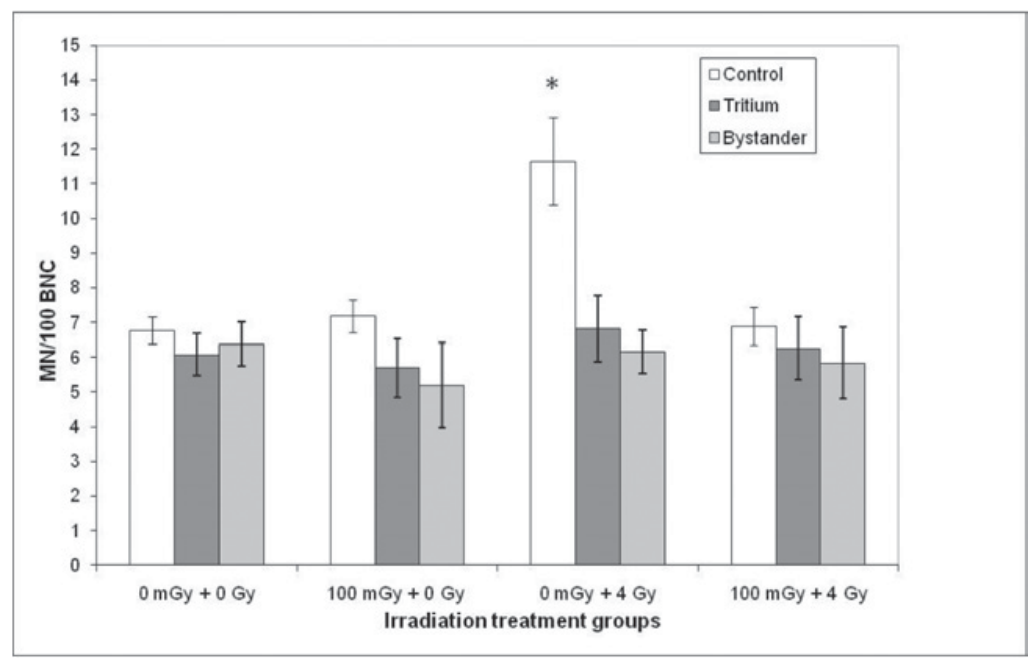

Figure 1. Micronucleus Frequencies for Different Irradiation Treatment (The error bars represent one standard deviation as calculated using the formula presented in Section 2.3 for the control data and one standard deviation with $\mathrm{n}=5$ for the tritium and bystander data). Significant differences are noted with an *.

\section{RESULTS AND DISCUSSION}

\subsection{Control micronucleus data (obtained from 1 animal)}

Figure 1 (white bars) presents the control micronucleus data graphically. A number of observations were made. First, it was noted that exposure to $100 \mathrm{mGy}{ }^{60} \mathrm{Co}$-gamma radiation did not increase the micronucleus frequency compared to controls (unexposed cells): no detrimental effects could be detected. The MN frequency obtained for the $0 \mathrm{mGy}$ and $100 \mathrm{mGy}$ treatments were 6.8 and 7.2 $\mathrm{MN} / 100 \mathrm{BNC}$, respectively. However, exposure of the cells to $4 \mathrm{~Gy}{ }^{60} \mathrm{Co}$-gamma radiation led to a marked increase in micronucleus frequency compared to control cells and cells exposed to $100 \mathrm{mGy}$ ${ }^{60} \mathrm{Co}$-gamma radiation. The micronucleus frequency was increased to $11.7 \mathrm{MN} / 100 \mathrm{BNC}$. Therefore, the higher dose was found to cause harm (DNA damage) to the test culture cells. Adaptive responses are inferred when the effect of a harmful challenge dose (high dose) is reduced by prior exposure to an adaptive dose (low dose). In this study, an adaptive response was measurable as the cells that were pre-exposed to $100 \mathrm{mGy} 3$ hours prior to being exposed to $4 \mathrm{~Gy}$ had markedly lower micronucleus frequencies compared to the cells that were exposed to $4 \mathrm{~Gy}$ alone. The MN frequency obtained for the $0 \mathrm{mGy}+4 \mathrm{~Gy}$ treatment and for the $100 \mathrm{mGy}+4 \mathrm{~Gy}$ treatment were 11.7 and $6.9 \mathrm{MN} / 100 \mathrm{BNC}$, respectively.

\subsection{Tritium micronucleus data (obtained from 5 animals)}

Figure 1 presents the pooled tritium micronucleus data graphically (dark grey bars). For each of these tadpoles (previously exposed to tritium and then placed in a background tank for a week), it was noted that exposure to $100 \mathrm{mGy}{ }^{60} \mathrm{Co}$-gamma radiation did not increase the micronucleus frequency. An average value of $6.1 \mathrm{MN} / 100 \mathrm{BNC}$ was obtained for the $0 \mathrm{mGy}$ treatment compared to an average value of 5.7 MN/100BNC for the $100 \mathrm{mGy}$ irradiation treatment. No detrimental effects of the $100 \mathrm{mGy}$ gamma radiation exposure could be detected (as for the control micronucleus data presented in Section 3.1).

Exposure of the cells to $4 \mathrm{~Gy}{ }^{60} \mathrm{Co}$-gamma radiation did not lead to a marked increase in micronucleus frequency in tadpoles previously exposed to tritium (contrary to what was observed with 
the control micronucleus data presented in Section 3.1). In fact, the average micronucleus frequency obtained following the 4 Gy irradiation treatment was only $6.8 \mathrm{MN} / 100 \mathrm{BNC}$. Therefore, the higher dose was found not to cause the expected harm (DNA damage) to the test cells. The cells seemed to behave like they were "adapted". They behaved like the $100 \mathrm{mGy}+4$ Gy cells described in Section 3.1.

The micronucleus frequencies in cells that were pre-exposed to $100 \mathrm{mGy} 3$ hours prior to being exposed to $4 \mathrm{~Gy}$ were similar to the micronucleus frequencies obtained in cells that were exposed to 4 Gy alone. Average values of 6.3 MN/100BNC and 6.8 MN/100BNC were obtained, respectively.

\subsection{Bystander micronucleus data (obtained from 5 animals)}

Figure 1 presents the pooled bystander micronucleus data graphically (light grey bars). For each of these tadpoles (placed in background tanks for a week with tadpoles that had been previously exposed to tritium), it was noted that exposure to $100 \mathrm{mGy}{ }^{60} \mathrm{Co}$-gamma radiation did not increase the micronucleus frequency. An average value of 6.4 MN/100 BNC was obtained for the $0 \mathrm{mGy}$ treatment compared to an average value of $5.2 \mathrm{MN} / 100 \mathrm{BNC}$ for the $100 \mathrm{mGy}$ irradiation treatment. No detrimental effects of the $100 \mathrm{mGy}$ gamma radiation exposure could be detected (as in Sections 3.1 and 3.2).

Exposure of the cells to $4 \mathrm{~Gy}{ }^{60} \mathrm{Co}$-gamma radiation did not lead to a marked increase in micronucleus frequency in bystander tadpoles (contrary to what was observed with the control micronucleus data presented in Section 3.1). In fact, the average micronucleus frequency obtained following the $4 \mathrm{~Gy}$ irradiation treatment was only 6.2 MN/100BNC. This value was comparable to the value obtained for the tritium micronucleus data presented in Section 3.2. Therefore, the higher dose was found not to cause the expected harm (DNA damage) to the test cells. The cells seemed to behave like they were "adapted". They behaved like the $100 \mathrm{mGy}+4$ Gy cells described in Section 3.1.

The micronucleus frequencies in cells that were pre-exposed to $100 \mathrm{mGy} 3$ hours prior to being exposed to $4 \mathrm{~Gy}$ were similar to the micronucleus frequencies obtained in cells that were exposed to 4 Gy alone. Average values of 5.8 MN/100BNC and 6.2 MN/100BNC were obtained, respectively.

\section{CONCLUSIONS}

Using the adaptive response (determined using micronucleus assay) as a biomarker, bystander effects in vivo / in vitro experiments were conducted on bullfrog tadpoles. The data obtained suggest that bystander effects do play a role in wild populations since bullfrog tadpoles that were not exposed to tritium responded like the tadpoles that were directly exposed to tritium after being placed in contact with them. This suggests that direct exposure to $3.0 \times 10^{4} \mathrm{~Bq} / \mathrm{L}$ tritium contributes to an increased resistance to a high dose of radiation in liver cells. It also suggests that being in contact to tadpoles that were previously exposed to $3.0 \times 10^{4} \mathrm{~Bq} / \mathrm{L}$ tritium (bystander effect) contributes to an increased resistance to a high dose of radiation in liver cells.

\section{References}

[1] Boreham, D.R., A. Trivedi and R.E.J. Mitchel. 1991. Radiation and stress response in Saccharomyces cerevisiae. In Prasad, R., Yeast Molecular Biology and Biotechnology (pp. 294314). New Delhi, India: Omega Scientific Publishers.

[2] Cai, L. and M.G. Cherian. 1996. Adaptive response to ionizing radiation-induced chromosome aberrations in rabbit lymphocytes: effect of pre-exposure to zinc, and copper salts. Mutat. Res., 369: 233-241.

[3] Flores, M.J., J. Pinero, T. Ortiz, N. Pastor, J.C. Mateos and F. Cortes. 1996. Both bovine and rabbit lymphocytes conditioned with hydrogen peroxide show an adaptive response to radiation damage. Mutat. Res., 372: 9-15. 
[4] Mitchel, R.E., N.J. Gragtmans and D.P. Morrison. 1990. Beta-radiation-induced resistance to MNNG initiation of papilloma but not carcinoma formation in mouse skin. Radiat. Res., 121: 180-186.

[5] Boreham, D.R., J.A. Dolling, S.R. Maves, S. Miller, D.P. Morrison and R.E. Mitchel. 1997. Heatinduced thermal tolerance and radiation resistance to apoptosis in human lymphocytes. Biochem. Cell Biol., 75: 393-397.

[6] Cregan, S.P., D.R. Boreham, P.R. Walker, D.L. Brown and R.E. Mitchel. 1994. Modification of radiation-induced apoptosis in radiation- or hyperthermia-adapted human lymphocytes. Biochem. Cell Biol., 72: 475-482.

[7] Ryan, L.A., C.B. Seymour, A. O’Neill-Mehlenbacher and C.E. Mothersill. 2008. Radiationinduced adaptive response in fish cell lines. J. Env. Radioactivity, 99: 739-747.

[8] Culley, D.D. (1992). Managing a Bullfrog Research Colony in "The Care and Use of Amphibians, Reptiles and Fish in Research”, Proceedings from a Scientists Centre for Animal Welfare (SCAW)/ Louisiana State University School of Veterinary Medicine (LSUSVM)-sponsored conference held April 8-9, 1991 in New Orleans, Louisiana with additional material provided by the authors (Published in November 1992), pp.30-39.

[9] Fenech, M., W.P. Chang, M. Kirsch-Volders, N. Holland, S. Bonassi and E. Zeiger. 2003. HUMN project: detailed description of the scoring criteria for the cytokinesis-block micronucleus assay using isolated human lymphocyte cultures. Mutat. Res. 534: 65-75. 